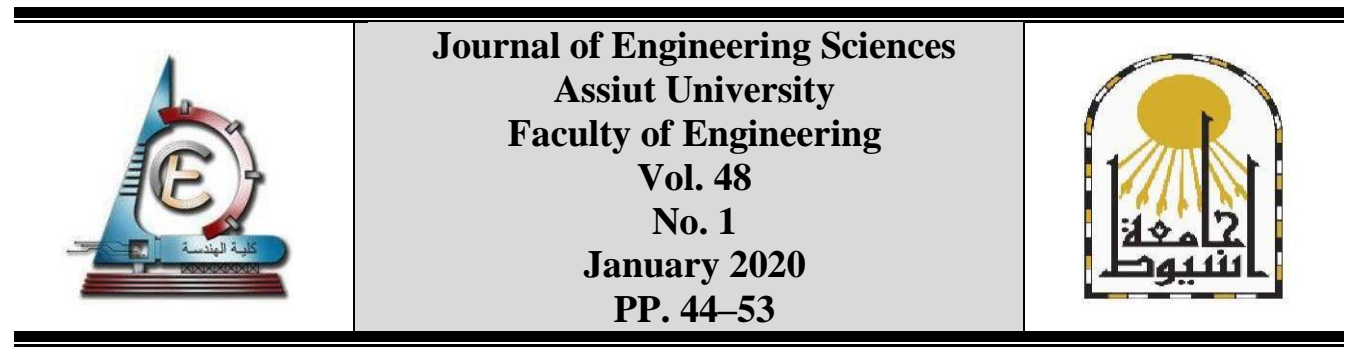

\title{
FINITE ELEMENT ANALYSIS AND EXPERIMENTAL INVESTIGATIONS ON HUB FORMING IN A SHEET BY THE HOLE EXPANDING TECHNIQUE
}

\author{
Samy Zein El-Abden * and Raghda Atef \\ Production Engineering and Mechanical Design Dept., Faculty of Engineering, Minia \\ University, Minia, EGYPT
}

Received 1 Augut 2019; Accepted 16 August 2019

\begin{abstract}
A numerical (finite element) simulation and experiments were carried out to form parts with hubs utilizing the hole expanding (HE) using different punch shapes (conical, flat and spherical) on AISI 1010 steel sheets with varying thickness $(0.8,1.00,1.5$ and $2 \mathrm{~mm})$. Five pre-hole diameters $(8,10,12,16$ and $20 \mathrm{~mm}$ ) were used. Effects of punch shape, sheet thickness and pre-hole diameter on load/displacement curves and failure modes were investigated. FE- predicted results showed that the punch shape, sheet thickness and pre-hole diameter were the controlling factors of the formability achieved in the process. From the experimental results, it was noticed that the required load was increased by increasing the sheet thickness and decreasing the pre-hole diameter. Effect of sheet thickness on the displacement at which maximum load occurs was not clear. FE simulation results proved to agree with to the experimental results reflecting the effect of controlling parameters and the beginning of damage modes. Limit processing curves, showing safe and unsafe regions could be determined.
\end{abstract}

Keywords: Hub forming by hole expanding, FE simulation, Punch geometry, damage modes, Forming limit curves.

\section{Introduction}

Hole expanding (HE) process is a typical sheet forming technique to produce formed hubs on sheet metal parts that have applications in many industries, e. g. engineering, medical and electronic. An oversized tool is introduced in a pre-hole in a sheet and pressed, causing the hole to expand producing a hub, see Fig. 1. The process variables are tool geometry, pre-hole diameter and thickness of expanding sheet.

\footnotetext{
* Crossponding author

E-mail address: sami.zein@minia.edu.eg
} 


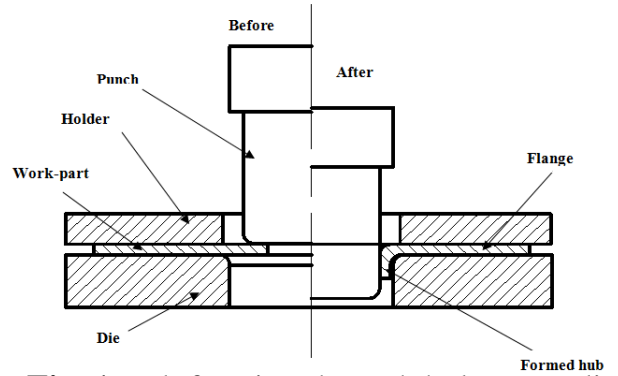

Fig. 1 Hub forming through hole expanding

Thesing et al [1] studied the HE process using the two punch geometries (conical and ellipsoidal) and different pre-hole diameter in martensitic steel sheets. The ellipsoidal punch had higher expansion ratios of small pre-hole diameters. Conical punch gave better results with higher pre-hole diameters. Dunckelmeyer et al [2] built an instrumented test rig to unify the HE test. Forming speed and force for clamping proved not to affect result in a noticeable manner. Load/displacement curve could be used to detect failure, hole edge deteriorated as force dropped. Paul et al [3] studied the experimental characterization of hole expansion ratio (HER) of steel sheet with different volume fractions of bainite, martensite, and bainitic ferrite to examine the expansion behavior and predicted of HER analytically from their tensile properties. Deformation modes could be predicted accurately through FEA. As through the thickness crack formation is the test stop criterion of the HE process, a fracture-based failure criterion was employed to predict the HER.

Lin et al [4] simulated the hole flanging by cold extrusion. They pointed that such process requires an excessive forming load when the punch directly applies on the top face of the whole blank. Soussi et al [5] used different hole diameter and clearance/thickness ratios in hole flanging. Failures appeared as tearing and necking. Necking occurred for large hole diameters, while successful parts were obtained when hole diameter is close to punch diameter. According to Kacem et al [6], clearance/thickness ratio proved to affect edge stretched flange and ironed flange. Experimental results proved to be close to FE findings. Lin et al [7] modeled hole-flanging for thick plate using an upsetting/flanging technique in several stages. The process resulted in an extended flange height and better hub geometry. Gopalakrishna et al [8] suggested split-sleeves with taper pin and ball methods. Holes were expanded from $2 \%$ to $6 \%$. Fatigue life was enhanced and was higher for taper pin method.

Kacem et al [9] studied two modes of fracture in the hole flanging of A1050-H14 and A6061-O alloy: orange peeling with and without ironing and radial fracture. Damage in the process was FE-modeled using a ductile fracture criterion. The hole expansion of a hub-hole of SAPH440, CT440 and FB590 steel sheets was studied by Ko, et al [10] using FEA with ABAQUS/program. The new proposed ductile fracture criteria used could predict the occurrence of the fracture and the extent of the expansion ratio. Huang and Chien [11] studied the hole flanging of circular plate with smaller pre-hole diameters located at the center. The Elasto-plastic FEA was applied to estimate the limitation of formability. The maximum ratio between the diameter of the punch and a minimum diameter of the hole was not affected by radii of punch profile, but the inner product surface and maximum load obtainable were dependent on the radii of punch profile. The same trend was concluded by Tang [12]. Dewang et al [13] showed that the punch die clearance and the initial flange length affected the edge cracking along the profile of die radius and distribution of strain. Lately, incremental sheet forming was utilized in the hole 
flanging process. Centeno et al [14] addressed the attributes of the process, mainly measured strain, formability limits by necking and fractures. The process gave rise to a different mode of deformation and that failure occurred by fracture without former localized necking. Dewang et al [15] studied both the one stage conventional and multi stage incremental flanging process using axi-symmetric conditions modeling technique and experiments. The successful forming limit was obtained with incremental forming technique with better dimensional accuracy and shape control over conventional processes.

The objective of the present work is to investigate the hub forming process on AISI 1010 steel sheets utilizing the hole expansion with blank holding using different punch shapes. Effects of punch shape, sheet thickness and pre-hole diameter on the load/ displacement curves using the finite element (FE) simulation will be predicted. A comparison will be made between experimental data and FE findings using DEFORM 2D and 3D FE program. In the light of the experimental results, successful (safe) and unsuccessful (unsafe) processing regions were determined which can be used in industrial applications. Also, damage beginnings will be studied.

\section{Simulation modeling}

An Elasto-plastic FE simulation was applied to analyze the hub forming process of AISI 1010 steel sheet. The HE with blank holding using a die was accomplished by means of the computer program DEFORM 2D and 3D FE software. A perfectly rigid die surface was assumed. Frictional behavior between the expansion die and sheet interface was expressed by the Coulomb's law. Top die was allowed to move while bottom die/workpiece interface was fixed. Table 1 gives the values used in the simulation.

Table. 1.

Assumed variable values in the simulation

\begin{tabular}{|l|c|c|}
\hline \multicolumn{1}{|c|}{ Properties } & symbol & Values \\
\hline Coefficient of friction & $\mu$ & 0.08 \\
Expansion punch diameter & D punch & $25 \mathrm{~mm}$ \\
Pre- hole diameter & $\phi$ hole & $8,10,12,16$ and $20 \mathrm{~mm}$ \\
Specimen Material & - & AISI 1010 cold rolled sheet \\
Sheet thickness & $\mathrm{t}$ & $0.8,1.0,1.5$ and $2.0 \mathrm{~mm}$ \\
Clearance between the punch and the die & $\mathrm{C} / 2$ & $1.25 \mathrm{t}$ \\
Die diameters & D die & $27,27.5,28.75$, and $30 \mathrm{~mm}$ \\
Radius of inner edge die & R i.e.d. & $2 \mathrm{~mm}$ \\
Conical Punch tip angle & $\boldsymbol{\alpha 2}$ & 60 degree \\
Flat punch edge radius & R f.p.e. & $2 \mathrm{~mm}$ \\
Spherical punch radius & R S.p. & $12.5 \mathrm{~mm}$ \\
\hline
\end{tabular}

\subsection{Modeling results}

Modeling was carried out in all cases four sheet thickness, five hole diameters, three punch shape and coefficient of friction was fixed as 0.08 corresponding to the case of using polished punch. A typical illustration of the mesh before and after HE is given in Fig.2. Fig. 3 presents an example for the FE-predicted load/displacement curves for different sheet thickness values hole $=12 \mathrm{~mm}$ for the conical punch geometry. The load required for the process increases by increasing the sheet thickness. The highest maximum load values were achieved when a flat punch was used. Conical punch results came second while the lowest load values were achieved when spherical punch was used. The distance at which the maximum load value is 
obtained was about $6 \mathrm{~mm}$ for flat punch, $10.5 \mathrm{~mm}$ for spherical punch and $16 \mathrm{~mm}$ for conical punch. Effects of sheet thickness of the maximum load and the distance (position) at which maximum load which occurs will be compared to the experimental results.

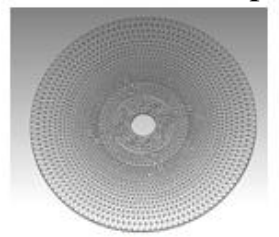

(a)

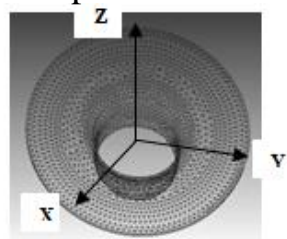

(b)

Fig. 2. FE grid mesh (a) before, and (b) after deformation

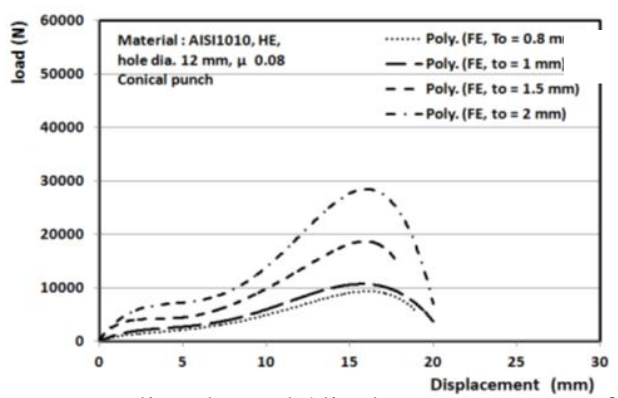

Fig. 3. An example of the FE-predicted Load /displacement curves for different sheet thickness,

$$
\mu=0.08, \phi \text { hole }=12 \mathrm{~mm} \text { and conical punch geometry }
$$

\section{Experimental work and results}

\subsection{Work material, specimen preparation and set up}

Work material was received in the form of AISI 1010 steel rectangular sheets, $1000 \mathrm{X}$ $1000 \mathrm{~mm}$ in various thickness (to), $0.8,1,1.5$ and $2 \mathrm{~mm}$. Work specimens were sheared to square blanks, 70x70 mm and holed to diameters 8, 10,12,16 and $20 \mathrm{~mm}$, see Fig. 4. Before and after expansion process are shown in Fig. 5a Schematics for experimental set up, expansion punch and dies are shown in Figs. 5b and Fig. 6. Grease was used as a lubricant.

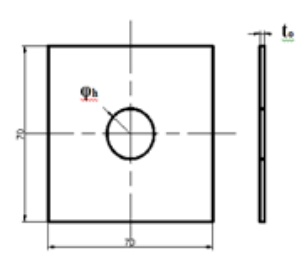

Fig. 4. Specimen geometry dimension in $\mathrm{mm}$

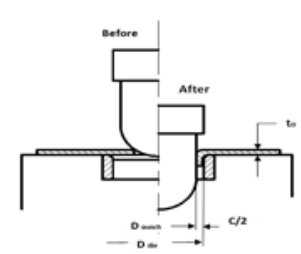

Fig. 5a. Before and after Expansion process

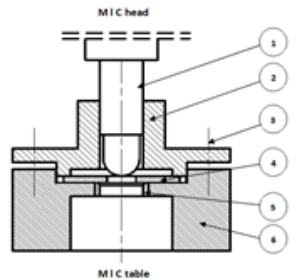

Fig. 5b. Schematic drawing of the experimental setup 1-Puuch. 2- Upper die. 3-Sheet blank 4-Die. 5- 4-Bolts $/ 90^{\circ} 6$ - Die block

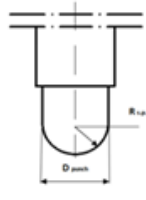

Conical punch

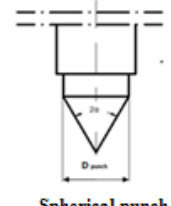

Spherical punch
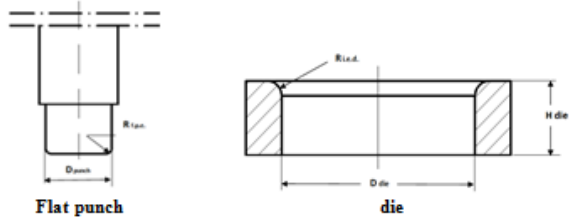

Fig. 6. Geometries of punches and die, dimensions in $\mathrm{mm}$

\subsection{HE experimental results}

Figs.7-9 show the load /displacement curves at different pre-hole diameters with to $=2$ 
mm using different punch geometries. Increasing the sheet thickness and decreasing the pre-hole diameter, the maximum load increases. The same trend was found for the other values of sheet thicknesses.

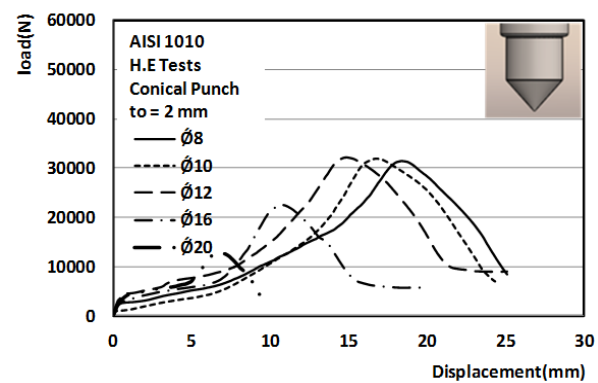

Fig. 7. Experimental load /displacement curves in HE experiments, different hole dia., conical punch

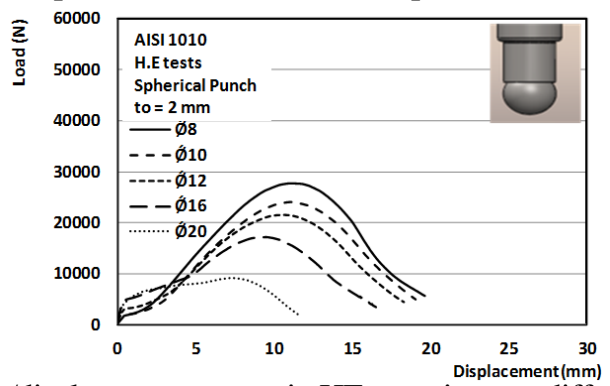

Fig. 8. Experimental load /displacement curves in HE experiments, different hole dia., spherical punch

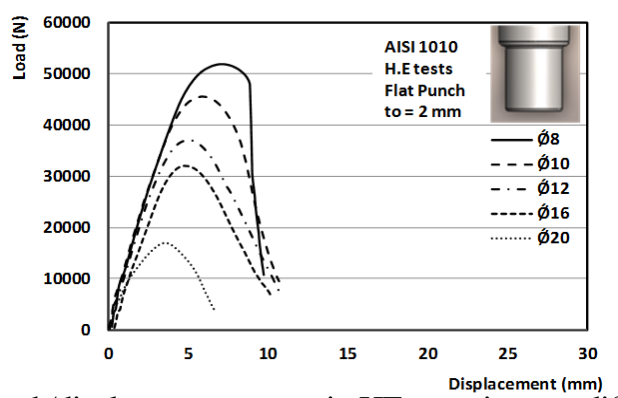

Fig. 9. Experimental load /displacement curves in HE experiments, different hole dia., flat punch

Fig. 10 illustrates an example of the effect of sheet thickness on maximum load in HE using a conical punch. The maximum load increases with increasing the thickness and decreasing the pre-hole diameter. Fig. 11 presents the effect of thickness on the distance at maximum load which occurs. There is no significant sign of a clear effect.

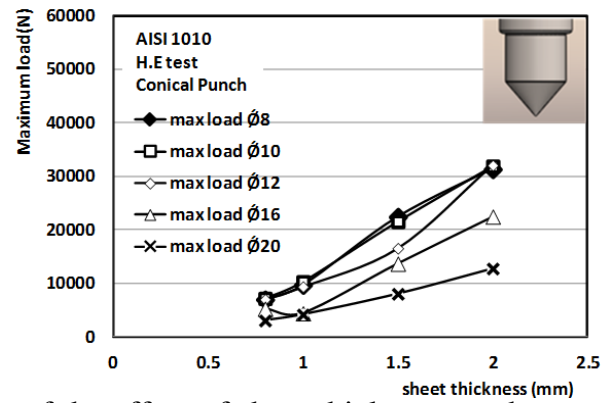

Fig. 10. An example of the effect of sheet thickness on the maximum load, conical punch 


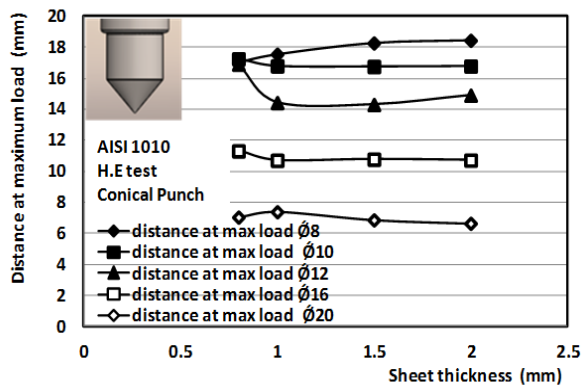

Fig. 11. An example of the effect of sheet thickness on the distance at which maximum load occurs, conical punch

\subsection{Fractography}

Sample fractures occurred during HE using conical punch appear in Fig. 12. Similar crack type appeared for the other punch geometries. Cracks started from the hub tip (refer to Kacem, et al [9]), then propagate to the hub wall. Fractures will often begin when the maximum generated strain in the circumferential direction on the deformed part reaches the maximum strain in simple tension, Soussi et al [5]. This is due to stretching of the extruded sheet of metal around the periphery direction. When the distance from the blankholding support to the edge of pre-hole diameter increases, the generating circumferential strain increases, Dewang et al [13].

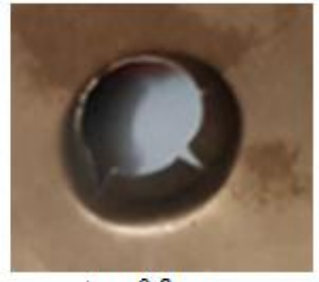

to $=0.8 \mathrm{~mm}$

hhole $=8 \mathrm{~mm}$

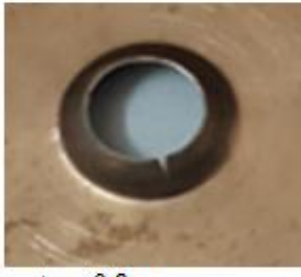

to $=0.8 \mathrm{~mm}$

thole $=10 \mathrm{~mm}$

Fig. 12. Fracture modes occur in the hole expansion test using conical punch

\subsection{Formability limit curves in hub forming of AISI 1010 steel}

Formability curves showing successful (safe) and unsuccessful (unsafe) regions within the tested range of sheet thickness and hole diameter for AISI 1010 steel for three different punch shapes were constructed, see Fig. 13. The percentage safe area (above the limit fracture line) in, HE was defined as:

$$
\% \text { safe area in } H E=\frac{\text { Safe area }}{\text { Total working }} \times 100
$$

Both total and safe areas are considered in units. The total working area included in this work was calculated from a rectangular area of the actual working range of both sheet thickness and hole diameter values, i. e., 0.8 to $2.0 \mathrm{~mm}$ and 0 to $20 \mathrm{~mm}$ respectively. The points plotted on the $\mathrm{Y}$-axis of zero are referred to the blind specimens (penetration experiments). The total working area of $(2.0-0.8) *(20-0)=24$ units represent $100 \%$. Safe area can be defined as the area at which the combination of sheet thickness and hole diameter gives successful hole expansion. The safe areas in HE with conical, spherical and flat punch were 13, 13.3 and 9.3 units, corresponding to $54.160 \%, 55.416 \%$ and $38.75 \%$ with respect to the total. It can be shown that the use of spherical punch has given the height percentage safe area, followed by the conical punch after which the flat punch gave the lowest value. 


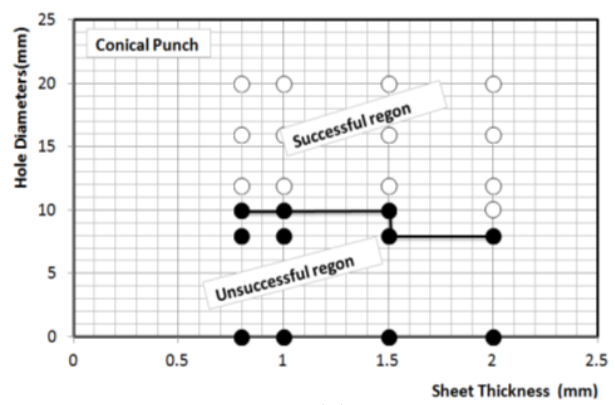

(a)

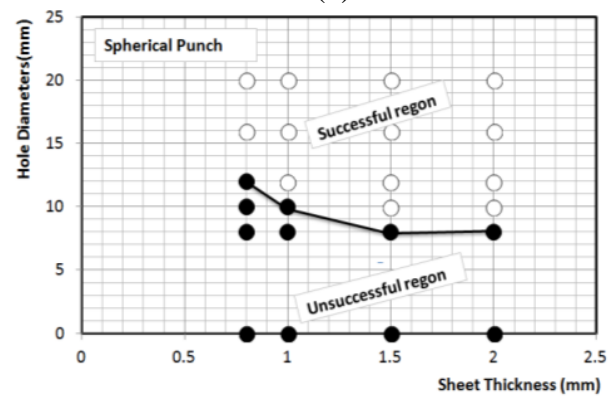

(b)

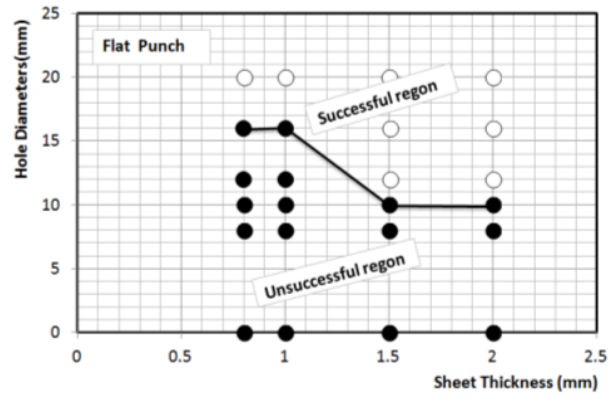

(c)

Fig. 13. Forming limit curves in hub forming of AISI 1010 steel sheets a) Conical punch, b) Spherical punch and c) Flat punch.

\section{Comparison between FE and experimental results}

Fig. 14 shows the experimental and the FE load/displacement curves in the HE of different sheet thickness with hole diameters of $12 \mathrm{~mm}$ in the grease - lubricated condition for different punch shapes. Good agreement was found. Fig. 15a presents a comparison between experimental and FE results of maximum load for different sheet thickness in HE of $12 \mathrm{~mm}$ hole diameter for different punch shapes. Fig. 15b presents the same comparison, but for the distance at maximum load which occurs. The agreement is excellent between the two results. 


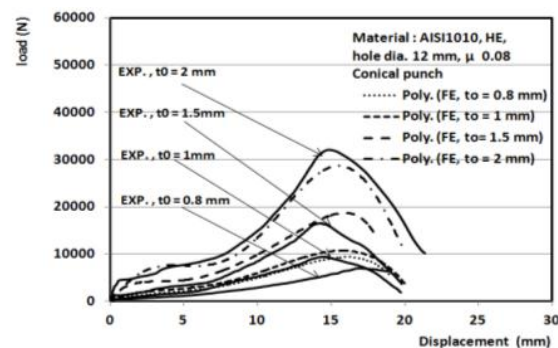

(a)

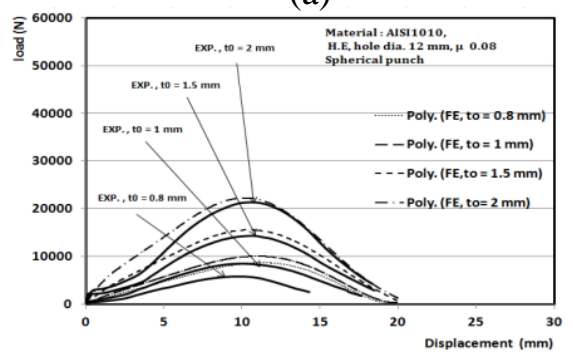

(b)

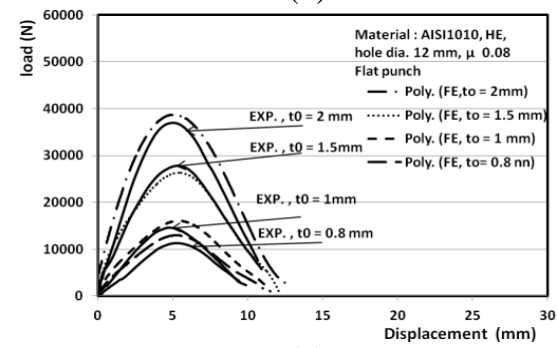

(c)

Fig. 14. Comparison between experimental and FE results of load/ displacement curve at hole diameter $12 \mathrm{~mm}$ with different sheet thickness using different punch shaps

a) Conical punch, b) Spherical punch and c) Flat punch

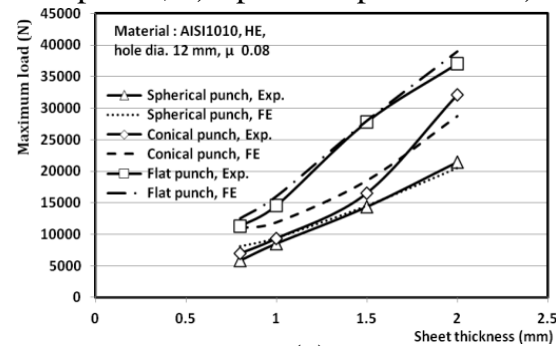

(a)

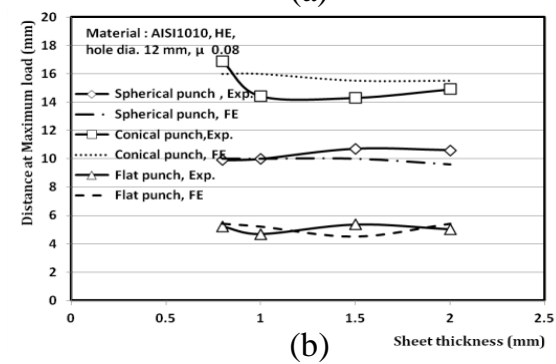

Fig. 15. Comparison between experimental and FE results of

(a) Maximum load vs. sheet thickness and (b) Distance at maximum load vs. sheet thickness for different punch shapes. 
Fig. 16 presents an example comparison between the experimentally obtained fractures (left) and FE-predicted damage initiation sites in the $\mathrm{HE}$ of $8 \mathrm{~mm}$ hole diameter and $0.8 \mathrm{~mm}$ thick sheet. Such damage sites predicted from the FE model (right) coincide with fracture sites obtained experimentally, confirming the suitability of the FEA in the treatment of this problem.

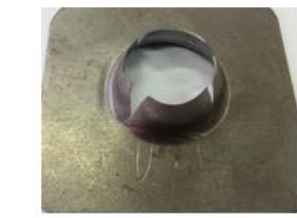

to $=0.8 \mathrm{~mm}$ ohole $=8 \mathrm{~mm}(\operatorname{Exp})$
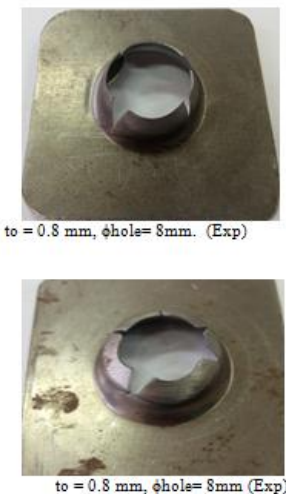

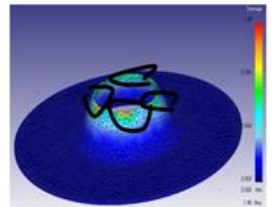

(a)

to $=0.8 \mathrm{~mm}$ ohole $=8 \mathrm{~mm}$. (FE results) to $=0.8 \mathrm{~mm}$, ohole $=8 \mathrm{~mm}$. (FE results)

(b)

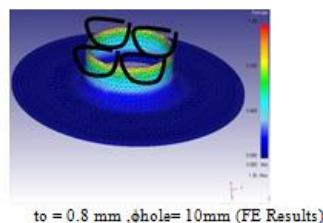

Fig. 16. Comparison between experimentally-obtaind fractures (left) and FE- predicted damage sites (right) using different punch shapes

a) Conical punch, b) Spherical punch and c) Flat punch

\section{Conclusions}

From the FE simulation modeling and the experimental results on the hub forming using hole expanding of AISI 1010 steel sheets with blank holding using different punch shapes, it can be concluded that:

1-Hub forming of AISI 1010 steel sheets with blank holding using different punch shapes could be FE-modeled and load/displacement curves could be derived reflecting the effects of the controlling parameters (sheet thickness, pre-hole diameter and punch shape). The highest maximum load was obtained when a flat punch was used, followed by use of conical punch and then when spherical punch was used.

2-Forming limit curves (FLC's) could be constructed for the range of sheet thickness and hole diameter chosen in the HE process of AISI 1010 steel sheets. Successful (safe) areas on the curves were determined. Spherical punch has given the height percentage safe area, followed by the conical punch after which the flat punch gave the lowest value.

3-Both the FE simulation findings and experimental results proved to have very good agreements. Such agreements included load/displacement curves, maximum loads and the distance at which such load occurs. Resulting experimental fracture modes coincided with the FE prediction. This type of analysis is capable of dealing successfully with such type of problem.

\section{Acknowledgement}

The experimental work described in this paper was performed at the Material Forming Lab, Faculty of Engineering, Minia University, Minia EGYPT. Thanks are due to Nour-Elhoda Hussein, the Lab engineer for her help in conducting the experiments. 


\section{REFERENCES}

[1] L.A Thesing,. U. Boff,. L. Schaeffer, Experimental Investigation of the hole Expansion Capability of A Martensitic AHSS Steel with Two Punch geometries and A Varity of Hole Diameters, International Journal of Materials Engineering and Technology, Vol.15, No. 2-3, (2016), pp.159-170.

[2] M. Dunckelmeyer, A. Karelova, C .Krempaszky, E. Werner, Instrumented hole expansion test, Proceedings of International Doctoral Seminar 2009, 17 - 19 May Smolenice Castle.

[3] S.K. Paul, M. Mukherjee, S. Kundu, S. Chandra, Prediction of hole expansion ratio for automotive grade steels, Computational Materials Science, Vol. 89, (2014), pp.189-197.

[4] H-S. Lin, C-Y. Lee, C-H. Wu, Hole flanging with cold extrusion on sheet metals by FE simulation, International Journal of Machine Tools \& Manufacture Vol. 47, (2007), pp. 168-174.

[5] H. Soussi, N. Masmoudi, A. Krichen, Analysis of geometrical parameters and occurrence of defects in th hole-flanging process on thin sheet metal, Journal of Materials Processing Technology, Vol. 234, (2016), pp. 228-242.

[6] A. Kacem, A. Krichen, P-Y. Manach, Occurrence and effect of ironing in the hole-flanging process, Journal of Materials Processing Technology, Vol. 211, (2011), pp. 1606- 1613.

[7] Q-Q. Lin, W-Z. Dong, Z-G. Wang, K. Hirsawa, A new hole-flanging method for thick plate by upsetting process, Transactions Nonferrous Metals Society China, Vol. 24, (2014), pp. 2387-2392.

[8] H.D. Gopalakrishna, H.N.N. Murthy, M. Krishna, M.S. Vinod, A.V. Suresh, Cold expansion of holes and resulting fatigue life enhancement and residual stresses in Al 2024 T3 alloy - An experimental study, Engineering Failure Analysis Vol. 17, (2010), pp. 361-368.

[9] A. Kacem, A. Krichen, P.Y. Manach, S. Thuillier, J.W. Yoon, Failure prediction in the holeflanging process of aluminum alloys, Engineering Fracture Mechanics, Vol. 99, (2013), pp. 251-265.

[10] Ko, Y.K. Lee, J.S. Huha, H. Kim, H.K. Park, S.H. Prediction of fracture in hub-hole expanding process using a new ductile fracture criterion, Journal of Materials Processing Technology, Vol. 187-188, (2007), pp. 358-362.

[11] Y-M. Huang and K-H. Chien, Influence of the punch profile on the limitation of formability in the hole flanging process, journal of materials processing Technology, Vol. 113, (2001), pp.720-724.

[12] S. C. Tang, Large Elasto-Plastic Strain Analysis of Flanged Hole Forming, Computer and structures, Vol. 13, (1981), pp. 363-370.

[13] Y. Dewang, M.S. Hora, S.K. Panthi, Finite element analysis of non axi-symmetric stretch flanging process for prediction the location of failure, Procedia Materials Science, Vol. 5, (2014), pp. 2054-2062.

[14] G. Centeno, M.B. Silva, V.A.M. Cristino, C. Vallellano, P.A.F. Martins, Hole-flanging by incremental sheet forming, International Journal of Machine Tools \& Manufacture, Vol. 59, (2012), pp. 46-54.

[15] Y. Dewang, R. Purohit, N. Tenguria, A study on sheet metal hole-flanging process, 6th International Conference of Materials Processing and Characterization, Proceedings 4, (2017), pp.5421-5428.
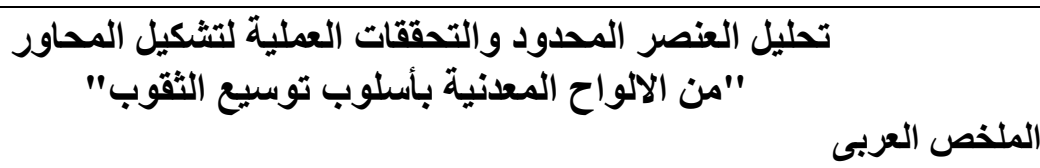

تم اجر اء النمذجة الرقمية (العنصر المحدود) و التجارب المعطلية لتشكيل اجز اء ذات محاور من الالو اح المعنية بأسلوب توسيع

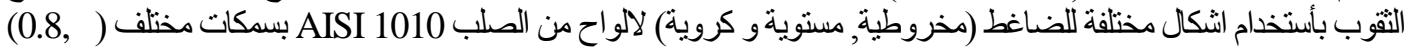

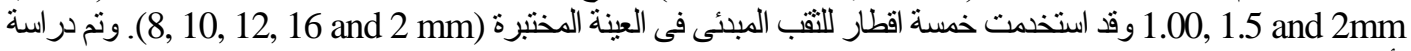

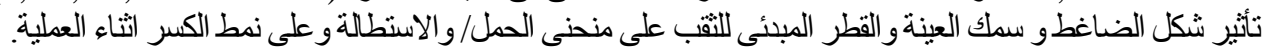

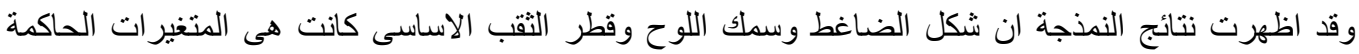

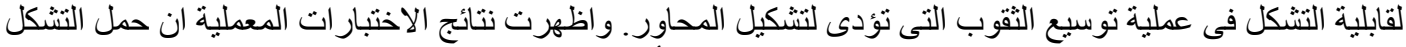

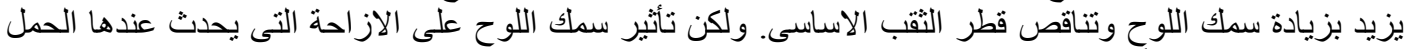

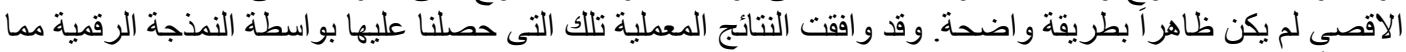

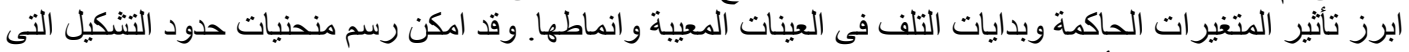
تظهر ظروف التشكيل الأمن او المحتمل البخر المخاطر للمادة المستخدمة. 